\title{
Overview of Microgravity Combustion Research at NASA Lewis Research Center and its Potential Commercial Impact
}

Valerie Lyons and Robert Friedman

Lewis Research Center

Cleveland, Ohio

Prepared for the

Space Technology and Applications International Forum cosponsored by the Defense Nuclear Agency, NASA, U.S. Department of Energy, and U.S. Air Force Albuquerque, New Mexico, January 26 -30, 1997

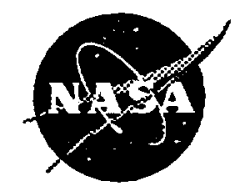

National Aeronautics and Space Administration 
- 


\title{
OVERVIEW OF MICROGRAVITY COMBUSTION RESEARCH AT NASA LEWIS RESEARCH CENTER AND ITS POTENTIAL COMMERCIAL IMPACT
}

\author{
Valerie Lyons and Robert Friedman \\ NASA Lewis Research Center \\ Cleveland $\mathrm{OH} 44135$ \\ (216) 433-5970 and 433-5697
}

\begin{abstract}
The near-zero (microgravity) environment of orbiting spacecraft minimizes buoyant flows, greatly simplifying combustion processes and isolating important phenomena ordinarily concealed by the overwhelming gravity-driven forces and flows. Fundamental combustion understanding has greatly benefited from analyses and experiments conducted in the microgravity environment. Because of the economic and commercial importance of combustion in practice, there is strong motivation to seek wider applications for the microgravity-combustion findings. This paper reviews selected technology developments to illustrate some emerging applications. Topics cover improved fire-safety technology in spacecraft and terrestrial systems, innovative combustor designs for aerospace and ground propulsion, applied sensors and controls for combustion processes, and self-sustaining synthesis techniques for advanced materials.
\end{abstract}

\section{INTRODUCTION}

Combustion reactions are the dominant mode of energy production for transportation, electric power generation, industrial furnaces, and habitat heating. Combustion is the principal reaction in the creation of many commodities, such as the refining of metals or the synthesis of plastics and ceramics. Combustion is also essential to a wide range of industrial operations, including process heating, pollution control, waste incineration, cutting, brazing, and welding.

Access to the non-convective, microgravity environment in orbiting and ballistic-trajectory spacecraft or in ground-based, free-fall facilities has proven to be highly advantageous for combustion research (Law 1994). In microgravity, buoyancy-induced flows are nearly eliminated, permitting the isolation of normally obscured forces and flows, the creation of simplified symmetries (isolated fuel particles, for example), and the expansion of experimental time and length scales without disturbances (NASA 1995).

\section{SELECTED MICROGRAVTTY COMBUSTION TEST RESULTS}

Analytical and experimental microgravity-combustion research conducted over the past three decades or more has investigated combustion in a wide variety of systems, such as premixed and diffusing gases, liquid droplets and pools, solid surfaces, and mixed phases (NASA 1995). Three combustion phenomena are highlighted in the following sections to illustrate promising sources for practical applications.

\section{Solid-Surface Combustion}

Fire-safety technology for spacecraft can benefit from the knowledge of ignition and flame spread along solid surfaces. In a microgravity environment, ignition may readily occur, but the resulting flame may not propagate because of the lack of induced flow of oxygen into the flame zone. Space experiments have demonstrated this selfextinguishment for fires initiated over certain surfaces, such as wire insulations or thick materials (Greenberg 1994, Rygh 1995). On the other hand, experiments on thin fuels (paper) show that slow but uniform flame spread is possible in quiescent microgravity (Olson 1988). In all of these fire situations, however, the addition of low-speed forced-air flows (i.e., spacecraft ventilation) can increase the flammability and rate of flame spread. Forced-flow flame-spread rates may be comparable to, or even exceed those in normal gravity (Olson 1988).

The microgravity flame appearance also differs from that associated with conventional, normal-gravity combustion. Typically, the microgravity flames are larger, dimmer, and stand off further from the fuel surface, 
compared to their normal-gravity counterparts (Grayson 1994). Other distinguishing features of microgravity flames in gaseous, liquid, and solid-phase systems are described in the literature (Law 1994, NASA 1995, Ramachandra 1995). Investigators report that, in many instances, microgravity flames in quiescent, standard-air conditions are so pale that they are difficult to observe (Rygh 1995). Visibility is greatly enhanced under conditions of forced-air flows or highoxygen concentrations, where microgravity flames are typically brighter and yellow in color. The visible appearance of the incipient fire is one of the "signatures" used for the remote detection of fires and for alarm criteria.

\section{Droplet Combustion}

Combustion of sprays of liquid droplets is a common process in propulsion systems and power-generating equipment. A thorough understanding of this combustion process is important for analyses and modeling to promote designs with efficient combustion and reduced exhaust emissions. The isolation of droplets for research is very difficult on Earth because of the motions and distortions caused by the buoyancy-induced flows and forces, and such studies must be limited to relatively small droplets. In microgravity, near-spherical droplets can be generated and maintained for idealized studies of their ignition and flame behavior. The range of microgravity droplet-combustion research covers the burning of pure- and multi-component fuel droplets, in single, double, and multiple-droplet arrays, and in quiescent or low-speed air-flow environments. Most important, the microgravity environment permits the generation, isolation, and observation of representative droplets, as large as 2 to $6 \mathrm{~mm}$ in diameter (NASA 1995).

Typical burning droplets appear quite different in quiescent and forced-flow microgravity. The quiescent droplet is surrounded by a soot shell and a concentric flame. The soot shell may not be visible under forced flow. Hydrocarbon-droplet combustion initiates with bright, sooty flames, which become less luminous with time. The flame luminosity increases with forced air flow, similar to the phenomena observed with solid-surface flames. Disruptive, almost explosive, burning is noted for bi-component mixtures with greatly differing component volatility. This behavior results from the expansion of the more volatile fuel as a "bubble" through the shell of the less volatile fuel (NASA 1995).

\section{Soot Formation}

Soot is an aggregate of solid, carbonaceous pyrolysis- and combustion-product particles. Soot has a high radiative emissivity, and it substantially increases the visibility of, and the radiative transport from, flames. Hence, bright, sooty flames are desirable for efficient energy extraction in fumaces and power equipment. In contrast, sootenhanced radiation is undesirable in film-cooled propulsion systems, causing decreased life in jet-engine combustion liners, for example.

Due to minimal buoyant motion, soot residence times in the microgravity combustion zone are relatively long; and, consequently, soot-particle concentration and morphology vary from these characteristics in normal gravity. Microgravity gaseous and liquid-droplet flames, even in quiescent environments, are often sootier than in normal gravity (Choi 1993, Ito 1994). Microgravity conditions greatly aid the isolation and collection of soot particles. Statistical analyses of particles collected from buming wire insulations indicate that both primary soot particles and their aggregates are several times larger in microgravity than in normal gravity (Paul 1993).

The differences in soot evolution and characteristics in microgravity have practical significance not only for power and pollution applications but also for fire safety through smoke detection. For optimum sensitivity and falsealarm rejection, smoke detectors are tuned for the expected particle-size distribution. Obviously, the setpoints for spacecraft smoke detectors can differ from those of typical terrestrial smoke detectors. Studies are now in progress to examine the response and alarm requirements of spacecraft smoke detectors based on typical incipient-fire scenarios anticipated in spacecraft operations (Urban 1995).

\section{SURVEY OF COMBUSTION APPLICATIONS AND OPPORTUNITIES}

The application of combustion fundamentals found through microgravity research to commercial opportunities is the focus of a new NASA initiative (Friedman 1996). A brief overview of the potential application areas follows. 


\section{Fire Safety}

Current spacecraft fire-protection designs and operations are based on terrestrial standards and testing, although there is a growing awareness of the need to apply microgravity-combustion knowledge to improve and optimize spacecraft fire safety (Friedman 1993). Certain fire scenarios have some probability of occurrence in spacecraft (Friedman 1992-3). For example, thermally stressed components may be prone to overheating and ignition, since the near-absence of natural-convective flows in microgravity greatly reduces air cooling. Again, aerosol clouds or fluid leaks may persist in the atmosphere as potential fire hazards, since settling and dispersion are very slow. Finally, smoldering, a low-temperature non-flaming reaction, may initiate readily in the absence of natural convection in spacecraft.

The first line of spacecraft fire-safety defense is in prevention, through strict material selection, low electricalwire current ratings, fusing, and electrical grounding. Material-acceptance tests are presently conducted in normal gravity to provide a "worst-case" simulation to spacecraft conditions. Recent research indicates, however, that this safety factor may not always apply. Some materials and ventilation conditions have been shown to promote flame spread in microgravity at rates that equal or exceed those in reference normal-gravity environments (Olson 1988, Tien 1990). The evaluation of material flammability in microgravity on any practical scale is, of course, impossible. Thus, one aim of microgravity-combustion research is to develop models and correlations of normal-gravity to ventilated microgravity fire-spread resistance useful for construction of databases of acceptable materials for spacecraft service.

Microgravity research may also assist the development of commodity materials with improved fire and pyrolysis resistance. One example is polytetrafluoroethylene (PTFE) polymer, which is widely used as a wire insulation in spacecraft and aircraft. The degradation of PTFE upon overheating generates toxic gases and ultrafine particles that are hazardous to the lungs (Todd 1993). New formulations of this polymer that may resist this degradation are under investigation.

The second line of fire protection is the detection and suppression of incipient fires. In Shuttle operations to date, five minor overheating events have occurred, none progressing to flaming fires. In all cases, the breakdowns were detected by the senses of the crew and promptly alleviated (Friedman 1992-3). Modern spacecraft are also equipped with automatic smoke detectors, which are adaptations of standard terrestrial designs. Studies of smoke density and soot characteristics from microgravity fires are in progress to improve the sensitivity and alarm criteria for space smoke detectors. These studies may also prove valuable for improved designs and operational criteria in terrestrial smoke detectors, in their ability to isolate, collect, and analyze smoke constituents.

None of the reported fire-threatening events in U.S. spaceflight missions required active fire suppression. Fire extinguishers are carried on all current human-crew spacecraft, nonetheless. The Shuttle has both portable and remotely actuated fire extinguishers, charged with Halon 1301 . Most of the inhabited modules of the International Space Station, now in construction, will be equipped with portable fire extinguishers charged with carbon dioxide. Exceptions are the Russian cabins, which carry a mixed-phase foam agent, and the decompression-treatment chamber, which may carry nitrogen. Spacecraft fire-suppression system designs and operations most likely could be standardized if research data were available on optimum physical dispersion, suppression effectiveness, and post-fire cleanup in microgravity Suppression experiments with adequate time and physical scales to demonstrate practical fire control are in the planning stages.

New fire suppression agents must be developed for both space and terrestrial applications that have: 1) low atmospheric ozone-depletion potential; 2) low global-warming potential; 3) low toxicity; and 4) the potential, preferably, to be a "drop in" replacement for Halons (similar vapor pressure, viscosity, etc.). One interesting alternative under investigation is a new use of old technology: water, formed into a very fine mist (Tapscott 1995).

\section{Combustors}

One of the goals of current NASA research in aeropropulsion combustion is the reduction of emissions from gas turbines (Lyons 1993, Ziemianski 1993). The control of exhaust pollutants such as oxides of nitrogen, carbon 
monoxide, unburned hydrocarbons, aerosols, and soot requires an in-depth knowledge of the physics and chemistry of combustion processes. Microgravity research offers new insights in combustion science in may fundamental ways, including the mechanisms of droplet combustion and soot formation. Application of this information can be used to assist in the design of fuel injectors for low-emission combustors. Experimental data can be used directly to determine fuel-spray effects on emissions, or they can validate advanced combustor codes to aid future design efforts. Of particular interest currently is supercritical droplet combustion, which has application to high-pressure combustors in both rocket motors and advanced aircraft engines.

Other combustion technologies can be linked to potential microgravity-combustion-science research. Particle coalescence and agglomeration can be studied in a simplified flow field in microgravity, where drag can be decoupled from other parameters affecting growth. A better understanding of the particle-formation process may increase the collection efficiencies of electrostatic precipitators for submicron particles. The combustion of tiny suspended coal particles in a microgravity environment can enable the study of the major processes involved in producing fly ash. Microgravity, which allows a surface-initiated reaction to transition to a homogeneous reaction without the interference of buoyancy, will also aid the study of catalytic combustion, a useful means of reducing emissions from many combustion systems. Also, the use of combustion synthesis to create new, uniformly-porous materials, a subject to be discussed later, will promote the development of improved catalytic substrates.

An indirect application of microgravity-combustion research is that of an apparatus developed for the study of premixed conical flames in upward and downward gravity and in microgravity (Bédat 1995). A stabilizing ring was invented to maintain an extremely lean flame for the visualization studies. This patented device is now available for commercial license as a residential and industrial gas-burner component, permitting stable, efficient combustion at lean fuel-air ratios for greatly reduced $\mathrm{NO}_{\mathrm{x}}$ emissions (Kostiuk 1996).

\section{Sensors and Controls}

The application of measurement techniques derived in space studies to scientific and commercial purposes on Earth is among the recognized benefits of the space program. The latest NASA Spinoff magazine, for example, cites a number of products, such as optical and radiation sensors, computer enhancement techniques, strain gages, and fiberoptic transmitters, all derived directly or indirectly from spacecraft instrumentation (Haggerty 1995).

Microgravity-combustion research has promoted advances in diagnostic techniques, primarily because of the need for non-perturbing, rapid-response measurements of flame appearance, velocity, temperature, and chemical species in severe environments. The observation of flames often requires image enhancements because the flames are barely visible or weakly radiant. Drop-tower experiments require small, rapidly responding yet rugged instrumentation capable of withstanding large deceleration forces upon recovery at the conclusion of the drop test. Space-based experiments need small, reliable, light-weight instrumentation.

The commercial development of diagnostic techniques derived from microgravity-combustion research promises benefits to other applications such as aircraft or automotive-engine instrumentation. A recent survey of imaging methods describes a wide variety of promising technologies (Weiland 1995). One product that is now entering commercial production is a line-absorption-spectroscopy instrument originally developed for microgravity chemicalspecies measurements and tested in ground-based microgravity facilities. The instrument is now promoted as an online analyzer for industrial smoke control.

\section{Advanced Materials}

Material processing in spacecraft is already a well established field, with recognized potential for commercialization (Bayuzick 1988, Whitten 1995). The non-buoyant environment promotes the study and application of physical processing, with such benefits as precise phase separations, homogeneous compositional control, uniform large crystal growth, and containerless processing.

The predominant role of combustion in material syntheses and processing is certainly recognized, but the wide range of potential applications (and the influence of gravity) is often overlooked. Combustion synthesis, for example, 
is the basis for the commercial production of many commodity and reagent gases, powders, ceramics, plastics, and coatings. Gravity is inherent in these processes, enhancing or inhibiting the actions of contacting devices, scrubbers, separators, and heat and mass exchangers. Even small-scale microgravity-combustion studies can aid the understanding and improvement of these operations by idealizing the systems, simplifying the analysis of reactions and modeling, and by aiding the evaluation of alternative or innovative techniques.

The current thrust in microgravity-combustion applications relative to material syntheses obviously concentrates on methods yielding products of high unit value, such as advanced ceramics, intermetallics, or fullerenes. As an example, one can cite the progress in self-propagating high-temperature synthesis (SHS) (Merzhanov 1993). The SHS process is based on highly exothermic, self-sustaining reactions for the efficient production of many refractory, high-strength, and specialized ceramic, alloy, and composite materials from metal-powder reagents. In normal gravity, the SHS reactions, which generate high temperatures and fluid phases, are prone to gravity-driven flows, density gradients, and product segregation. Microgravity offers an environment free from these disturbances, enabling the analysis and optimization of the processes (Hunter 1994). Microgravity experiments can verify analytical predictions, and they can lead to a better understanding of the kinetics of the reaction and the phase control of the products.

Potential products obtained by SHS reactions may include ceramic fibers and whiskers, porous materials for filters and medical implants, glasses, as well as monolithic intermetallics. An interesting illustration of heterogeneous materials produced by SHS and the influence of gravity on the product morphology is seen in the work of A.S. Shteinberg of the Russian Institute of Structural Macrokinetics. In this study, titanium carbide is formed as a "foam" product through unconstrained expansion during the reaction from the elements. Regardless of the reaction orientation, gravity forces inhibit the expansion. In microgravity, a fully expanded, homogeneous porous product is obtained.

Particle synthesis in flames also offers the promise of low-cost manufacturing of non-oxide powders, such as uniform silicon-carbide particles. This effort could be linked to the study of ash formation in combustion processes.

\section{CONCLUDING REMARKS}

The non-convective, microgravity environment associated with orbiting spacecraft offers advantages for research that have greatly increased the fundamental knowledge of combustion science. Because of the great economic importance of combustion processes in practice, there is strong motivation to pursue the commercial applications of the research findings. Examples of technology developments now actively underway and described in this paper, include spacecraft and terrestrial fire safety, combustors for use in propulsion and power systems, applied sensors and controls (including diagnostic instrumentation), and advanced materials developed with self-propagating high-temperature synthesis (SHS).

\section{Acknowledgments}

This work was prepared with internal funds by Valerie Lyons and Robert Friedman at the NASA Lewis Research Center.

\section{References}

Bayuzick, RJ. (1988) "Space Processing of Metals and Alloys," in Commercial Opportunities in Space, Shahrokhi, F. C.C. Chao, and K.E. Harwell, eds., Prog. in Aero. and Astro. 110: 137-160.

Bédat, B., L.W. Kostiuk, and R.K. Cheng (1995) "Coupling of Wrinkled Laminar Flames with Gravity," in 3rd Internat. Microgravity Comb. Workshop, Ross, H.D., ed., NASA Conf. Publ. CP-10174, 395-400.

Choi, M.Y., et al. (1993) "Soot Agglomeration in Isolated, Free Droplet Combustion," ALAA Paper 93-0823.

Friedman, R. (1992-93) "Fire Safety Practices and Needs in Human Crew Spacecraft," Jour. Appl. Fire Safety, 2 (3): 243-259.

Friedman, R. and D.L. Urban (1993) "Contributions of Microgravity Test Results to the Design of Spacecraft Fire Safety Systems," ALAA Paper 93-1152. 
Friedman, R and V.J. Lyons (1996) "Potential Commercial Applications From Combustion and Fire Research in Space," ALAA Paper 96-4439.

Grayson, G., et al. (1994) "Flame Spreading Over a Thin Solid in Low-Speed Concurrent Flow3/4Drop Tower Experimental Results and Comparison with Theory," Micrograv. Sci. Technol. VII (2): 187-195.

Greenberg, P.S., K.R. Sacksteder, and T. Kashiwagi (1994) "Wire Insulation Flammability Experiment: USML-1

1 Year Post Mission Summary," in Joint Lounch + One Year Sci. Review of USML-1 and USMP-1 with the Micrograv. Meas. Group, Frazier, D.O., S.L. Lehoczky, and C.R. Baugher, eds., NASA Conf. Publ. CP-3272, vol. II, 631-655. Haggerty, J.J. (1996) "Spinoff 1995," NASA NP-217.

Hunter, K.R. and J.J. Moore (1994) "The Effect of Gravity on the Combustion Synthesis of Ceramic and CeramicMetal Composites," Jour. Mater. Synth. Proc. 2: 355-365.

Ito, H., O. Fujita, and K. Ito (1994) "Agglomeration of Soot Particles in Diffusion Flames Under Microgravity," Comb. and Flame 99: 363-370.

Kostiuk, L.W. and R.K. Cheng (1996) "Apparatus and Method for Burning a Lean, Premixed FueVAir Mixture with Low NOx Emission," U.S. Patent No. 5,516,280, 14 May.

Law, C.K. and G.M. Faeth (1994) "Opportunities and Challenges of Combustion in Microgravity" Prog. Energy Comb. Science 20: 65-113.

Lyons, V.J. and R.W. Niedzwiecki (1993) "Combustor Technology for Future Small Gas Turbine Aircraft," NASA TM 106312.

Merzhanov, A.G. (1993) "Theory and Practice of SHS: Worldwide State of the Art and the Newest Results," Internat. Jour. of Self-Propagating High-Temp. Synthesis, 2: 113-158.

NASA (1995) "Microgravity Combustion Science: 1995 Program Update," NASA TM 106858.

Olson, S.L., P.V. Ferkul, and J.S. Tien (1988) "Near-Limit Flame Spread Over a Thin Solid Fuel in Microgravity," in Twenty-Second Symp. (International) on Comb. The Combustion Inst, Pittsburgh, 1213-1222.

Paul, M.R., et al. (1993) "The Morphological Description of Particles Generated from Overheated Wire Insulations in Microgravity and Terrestrial Environments," in Heat Transfer in Microgravity Systems-1993, Sadhal, S.S. and A.

Hashemi, eds. ASME HTD 235: 59-66.

Priem, RJ. (1988) "Study of Industry Requirements That Can Be Fulfilled by Combustion Experimentation Aboard Space Station," NASA CR-180854.

Ramachandra, P.A., et al. "The Behavior of Flames Spreading Over Thin Solids in Microgravity," Comb. and Flame 100: 71-84.

Rygh, K. (1995) "Fire Safety Research in Microgravity: How to Detect Smoke and Flames You Cannot See," Fire Technol. 31: 175-185.

Tapscott, R., ed. (1995) "Chemical Options to Halons for Aircraft Use," DOT/FAA/CT-95/9.

Tien, J.S. (1990) "The Possibility of a Reversal of Material Flammability Ranking from Normal Gravity to Microgravity," Comb. and Flame 80: 355-357.

Todd, P. et al. (1993) "Physics, Chemistry and Pulmonary Sequelae of Thermodegradation Events in Long-Mission Space Flight," SAE Tech. Paper 932144.

Urban, D.L., et al.. (1995) "Smoke Detection in Low-G Fires," in 3rd Internat. Microgravity Comb. Workshop, Ross, H.D., ed. NASA Conf. Publ. CP-10174, 175-180.

Weiland, K.J. (1995) "Qualitative and Quantitative Imaging in Microgravity Combustion," in 3rd Internat. Microgravity Comb. Workshop, Ross, H.D., ed. NASA Conf. Publ. CP-10174, 291-302.

Whitten, R.P. and E.A.Gabris, (1995) "Commercial Space Processing," AlAA Paper 95-0389.

Ziemianski, J.A. and Ball, C.L. (1993) "Propulsion Technology Challenges for Turn-of-the-Century Commercial Aircraft," NASA TM 106192. 



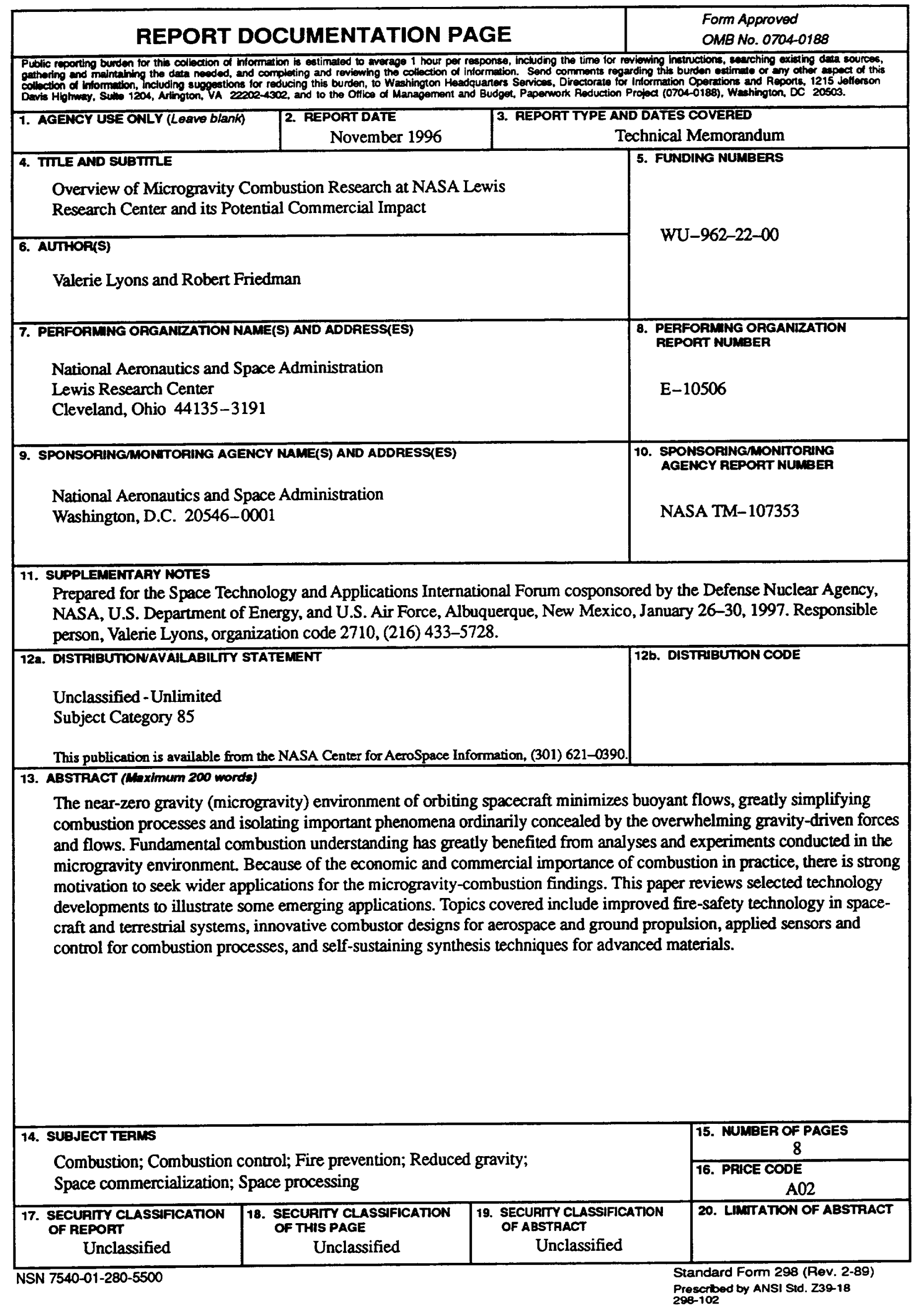

